\title{
Open Questions and the Manifest Image
}

\author{
MARK ELI KALDERON \\ University College London
}

\begin{abstract}
The essay argues that, on their usual metalinguistic reconstructions, the open question argument and Frege's puzzle are variants of the same argument. Each are arguments to a conclusion about a difference in meaning; each deploy compositionality as a premise; and each deploy a premise linking epistemic features of sentences with their meaning (which, given certain meaning-platonist assumptions, can be interpreted as a universal instantiation of Leibniz's law). Given these parallels, each is sound just in case the other is. They are, in fact, unsound. The essay first argues that reformulations of these arguments directly in terms of Leibniz's law are unsound and then that subarguments of the metalinguistic versions are unsound for structurally similar reasons. Finally, given how the theory/observation distinction is deployed in linguistic practice, the meaning-platonist assumptions are shown to be optional.
\end{abstract}

Shouldn't philosophers be permitted to rise above faith in grammar? All due respect for governesses_-but hasn't the time come for philosophy to renounce the faith of governesses?

FRIEDRICH NIETZSCHE, Beyond Good and Evil, 1886

\section{Introduction}

Moore's (1903) open question argument has exerted a tremendous influence on the thought and imagination of twentieth century metaethicists. After the centenary of its publication, perhaps it is time for a reassessment.

Indeed, reassessment is needed. The similarities between the open question argument and Frege's puzzle have so far been overlooked. As I will argue, they are variants of the same argument. But once one appreciates the parallel, much of the standard commentary on the open question argument and its role in the case for nonnaturalism is inadequate. Not only can we learn something about the open question argument by appreciating the parallel, but so too can we learn something about Frege's puzzle.

There is an intuitively obvious though hard to define distinction between normative and descriptive predicates. Normative predicates include good, right, rational, justified, and so on. As our examples suggest, normative 
predicates will be understood broadly enough to include both moral and nonmoral expressions. Descriptive predicates include blue, taller than, means, believes, and so on. ${ }^{1}$ The distinction is intuitively obvious at least in the sense that, over a wide range of cases, competent speakers can reliably classify predicates as normative or descriptive. There may be disagreement over recalcitrant cases. (Is dangerous a normative or descriptive predicate?) But where there is disagreement, this disagreement is substantive. The parties disagree about whether a given predicate is normative or descriptive; they need not disagree about the nature or existence of the linguistic distinction. As a working hypothesis I will assume that the distinction between normative and descriptive predicates constitutes a partition-that every predicate is normative or descriptive but not both.

There is a metaphysical distinction corresponding to this linguistic distinction. Thus I will speak of normative and descriptive properties. Every property is either normative or descriptive. But in order for the metaphysical distinction to constitute a partition, it must be the case that no property is both normative and descriptive. There are two ways to understand the metaphysical distinction:

1 Normative properties are distinct in kind from descriptive properties.

2 Normative properties are a distinct subkind of descriptive properties.

As my examples of descriptive predicates make clear, I will follow tradition in counting semantic predicates and the predicates of intentional psychology as descriptive predicates. This is controversial. If Kripke's (1980) Wittgenstein is to be believed, then such predicates are implicitly normative. Specifically, Kripke's Wittgenstein maintains that sentences such as:

Snow is white means in English that snow is white.

entail normative sentences such as:

A competent speaker of English should only assertively utter Snow is white

if snow is white.

and so the meaning ascription is itself a normative sentence. And similar reasoning purports to establish that propositional attitude ascriptions are themselves normative sentences. Not every philosopher agrees. (See Horwich, 1995, and Rosen, 1997.) Thus some maintain that all that is entailed is a conditional sentence:

If a competent speaker of English should only assertively utter true sentences, then a competent speaker of English should only assertively utter

Snow is white if snow is white.

and that this is insufficient to establish that the corresponding meaning ascription is a normative sentence. This is relevant to metaethical debate since many believe that if the normative is reducible to the descriptive, then a successful reduction will appeal to intentional-psychological properties. But if intentional-psychological properties are themselves normative, then no reduction has been effected. For the purposes of the present essay, however, I will assume that Kripke's critics are correct. 
Understood the former way, the metaphysical distinction constitutes a partition; understood the latter way, the metaphysical distinction does not. According to the former understanding, normative and descriptive properties differ in kind, and so no normative property is a descriptive property. But as every property would be normative or descriptive but not both, the metaphysical distinction would constitute a partition. According to the latter understanding, normative properties are a subkind of descriptive properties, and so some descriptive properties are normative properties. But while every property would be normative or descriptive, some descriptive properties would be normative, and so the metaphysical distinction would not constitute a partition. Moore is concerned to argue for the former understanding of the metaphysical distinction. Moral properties are normative properties, and Moore argues that moral properties differ in kind from descriptive properties-that moral properties are nonnatural properties. Given that Moore argues for this conclusion, we do not want to assume it at the outset. So while we will assume that every property is normative or descriptive, we will initially suspend judgment about whether any property is both normative and descriptive.

What is the relationship between the linguistic and metaphysical distinctions? I will assume that normative predicates denote normative properties (if they denote at all), and that descriptive predicates denote descriptive properties. I will not make the corresponding assumptions that only properties denoted by normative predicates are normative, and that only properties denoted by descriptive predicates are descriptive. These latter assumptions in conjunction with the assumption that the distinction between normative and descriptive predicates constitutes a partition would entail that the metaphysical distinction itself constitutes a partition. If every predicate were normative or descriptive but not both, and a property were normative or descriptive only if it were denoted by a normative or descriptive predicate, then every property would be normative or descriptive but not both. But this would beg the question against moral descriptivists.

\section{The Open Question Argument}

In arguing that goodness is a simple, indefinable property, Moore emphasizes that by definition he does not mean verbal definition, i.e., definitions of the form:

Good in English means...

Whereas verbal definitions are contingent, a posteriori, and synthetic, ${ }^{2}$ the definitions that Moore has in mind are necessary, a priori, and analytic.

Thus the word good could have been conventionally used to denote some property other than goodness. So the verbal definition of good is contingent. Moreover, experience is required in order to know the verbal definition of good. Indeed, as Moore explicitly rec- 
Moreover, Moore emphasizes that whereas verbal definitions have a linguistic subject matter (they are about the English word good), analytic definitions concern the nature of goodness. Moore's observation is an instance of the laudable injunction not to confuse use with mention. Unfortunately, his subsequent discussion fails, in large part, to observe this injunction. Moore's talk of indefinable properties prefigures this failure-whereas it makes sense to speak of a predicate as being indefinable, it does not make sense (except as a courtesy) to speak of the denoted property as being indefinable.

Could there be a nontrivial definition of the word good in purely descriptive vocabulary? Could good, for example, be defined as what we desire to desire? Moore believes that we can establish that the universal closure of the biconditional:

$\mathrm{x}$ is good iff $\mathrm{x}$ is what we desire to desire

is not a definition even if all and only good things were, in fact, what we desire to desire. If it were indeed a definition, then not only must its universal closure be true, but it must exhaustively determine the very meaning of the word good. But Moore believes that we can decisively establish that good and what we desire to desire are not synonyms.

Suppose the predicates good and what we desire to desire were indeed synonymous. Now consider the following question: ${ }^{3}$

Granted that $\mathrm{x}$ is what we desire to desire, is $\mathrm{x}$ good?

Moore maintains that no matter what you think the answer is, this question is just as intelligible as the following question:

Is $\mathrm{x}$ good?

But if good meant just the same as what we desire to desire, then we could always replace one with the other in any sentence without changing that

ognizes, establishing the truth of a verbal definition would require statistical evidence about the use of definiendum in the given linguistic community. So the verbal definition of good is a posteriori. Moreover, the verbal definition of good is synthetic. Notice a competent speaker that understands the sentence:

Bon in French means good.

may still lack sufficient evidence to know that the proposition that it expresses is true. By parity of reasoning, a competent speaker's understanding of a verbal definition of good would itself be insufficient to know that the proposition that it expresses is true. Since verbal definitions cannot be known by competent speakers solely on the basis of their understanding of them, verbal definitions are not analytic but are, rather, synthetic. Throughout questions are understood to be sentences in the interrogative mood. 
sentence's meaning. ${ }^{4}$ So if good were correctly defined as what we desire to desire, then the question:

Granted that $\mathrm{x}$ is what we desire to desire, is $\mathrm{x}$ good?

would mean just the same as the question:

Granted that $\mathrm{x}$ is good, is $\mathrm{x}$ good?

But whereas it is perfectly intelligible to ask the former question, it is absurd to ask the latter. Whereas the former question is open-merely understanding the question is not sufficient for knowing its answer, the latter question is closed-merely understanding the question is sufficient for knowing its answer. So these two questions do not mean the same, and thus good is nonsynonymous with what we desire to desire. But if good and what we desire to desire are nonsynonymous, then good is not correctly defined as what we desire to desire. ${ }^{5}$

Moore's method is perfectly general-no feature specific to the candidate definition was appealed to. So if the open question argument is a sound argument that good cannot be defined as what we desire to desire, it is the basis of a sound argument that good cannot be defined in terms of any descriptive predicate. One need only run the argument for every candidate descriptive definition. Though clearly intended by Moore, this generalization may be questioned. Perhaps we have yet to consider the appropriate descriptive definition. And when we do, perhaps the question of whether anything satisfying the definiens is good will be closed. This is a fair complaint. As such, Moore's full case against the possibility of descriptively defining good should be understood as a challenge: Give a descriptive definition of good

4 I am assuming that sentences express propositions relative to the context of utterance and that the proposition expressed by a sentence is what is said, among other things, in uttering that sentence in the given context. I am further assuming that propositions are the primary bearers of truth and falsity, and are the objects of attitudes such as belief and assertion. By the content of an expression, I mean that expression's contribution to the proposition expressed by the sentence in which it occurs (relative to the context of utterance). The meaning of an expression is not, in general, its content. Thus the content of context sensitive expressions, such as indexicals, can vary from context to context even though their meaning remains constant. Though the meaning and content of context sensitive expressions are distinct, I will make the simplifying assumption that the content of context insensitive expressions just is their meaning. (For the most part we will ignore context sensitivity.) Given these assumptions, the meaning of a context insensitive sentence is the proposition that it expresses.

This is a version of an argument standardly attributed to Moore. I do not mean to be engaged in Moorean exegesis here. (Indeed, there is room to doubt whether the argument standardly attributed to Moore is to be found in the Principia.) Rather, I mean only to consider an argument, widely attributed to Moore, that has played an important role in twentieth century metaethics. 
such that it is a closed question whether anything satisfying the definiens is good or disavow analytic descriptivism. ${ }^{6}$

Let $\mathbf{F}$ be any descriptive predicate. We can reconstruct Moore's argument more generally as follows:

\section{The Open Question Argument OQA}

P1 If the universal closure of the biconditional:

$\mathrm{x}$ is $\operatorname{good}$ iff $\mathrm{x}$ is $\mathrm{F}$

is a definition, then $\operatorname{good}$ and $\mathbf{F}$ are synonymous.

\section{P2 Compositionality}

Let $\mathbf{e}$ and $\mathbf{e}^{\prime}$ be expressions of the same grammatical category. If $\mathbf{S}[\ldots . . .$.$] and \mathbf{S}\left[. . . \mathbf{e}^{\prime} . ..\right]$ are sentences free of quotation contexts and $\mathbf{S}[. . . e . .$.$] is the result of substituting \mathbf{e}$ in for an occurrence of $\mathbf{e}^{\mathbf{\prime}}$ in the sentence $\mathbf{S}\left[\ldots \mathbf{e}^{\prime} . ..\right]$, then if $\mathbf{e}$ and $\mathbf{e}^{\prime}$ are synonymous, then $\mathbf{S}[\ldots . . . .$.$] and \mathbf{S}\left[\ldots \mathbf{e}^{\prime}\right.$... $]$ mean the same.

P3 The questions:

Q1 Granted that $\mathrm{x}$ is $\mathrm{F}$, is $\mathrm{x}$ good?

Q2 Granted that $x$ is good, is $x$ good?

differ only in the substitution of $\mathbf{g o o d}$ for an occurrence of $\mathbf{F}$.

P4 If $\operatorname{good}$ and $\mathbf{F}$ are synonymous, then Q1 and Q2 mean the same. From P3 \& Compositionality

P5 If Q1 and Q2 mean the same, then if a competent speaker who understands Q1 lacks sufficient evidence to know its answers (in which case Q1 is open), then a competent speaker who understands Q2 lacks sufficient evidence to know its answer (in which case Q2 is open).

P6 Q1 is open.

Moore's argument is general in another way. If it is a sound argument that there is no descriptive definition of good, it is the basis of a sound argument that there is no descriptive definition of any moral predicate. One need only issue the corresponding Moorean challenge for every moral predicate. Moore, of course, maintains that right is definable, but he denies that it is definable in purely descriptive idiom. The correct definition of right essentially involves the predicate good:

An action is right in circumstances $\mathrm{c}$ iff it produces more good consequences than any alternative action that is open to the agent in c. 
P7 Q2 is not open.

P8 Q1 and Q2 do not mean the same. From P5, P6 \& P7 by modus tollens

P9 Good and $\mathbf{F}$ are not synonymous. From P4 \& P8 by modus tollens

C The universal closure of the biconditional:

$\mathrm{x}$ is good iff $\mathrm{x}$ is $\mathrm{F}$

is not a definition. From $P 9 \& P 1$ by modus tollens

So reconstructed, Moore's open question argument is a close variant of Frege's puzzle. Frege (1892/1984) provides an apparent reductio of a commonsense view of the meanings of names:

\section{Millianism}

The meaning of a name is the object that it denotes.

Hesperus and Phosphorus are names for the same object, Venus. So if the meaning of a name were the object that it denotes, then Hesperus and Phosphorus must mean the same. But Frege believes that we can decisively establish that Hesperus and Phosphorus are not synonyms.

Suppose the names Hesperus and Phosphorus were indeed synonymous. Now consider the following sentence:

Hesperus is visible in the evening.

Frege observes that the ancient astronomers possessed sufficient evidence to accept this sentence. But if Hesperus meant just the same as Phosphorus, then we could always replace one with the other in any sentence without changing that sentence's meaning. So if the meaning of a name were the object that it denotes, then the sentence:

Hesperus is visible in the evening.

would mean just the same as the sentence:

Phosphorus is visible in the evening.

But whereas the ancient astronomers possessed sufficient evidence to accept the former sentence, they lacked sufficient evidence to accept the latter. So these two sentences do not mean the same, and thus Hesperus is nonsynonymous with Phosphorus. But if Hesperus and Phosphorus are non- 
synonymous despite denoting the same object, then the meaning of a name is not the object that it denotes.

We can reconstruct Frege's puzzle as the following argument:

Frege's Puzzle FP

P1 If the meaning of a name is the object that it denotes, then if Hesperus and Phosphorus denote the same object, then Hesperus and Phosphorus are synonymous.

\section{P2 Compositionality}

Let $\mathbf{e}$ and $\mathbf{e}^{\prime}$ be expressions of the same grammatical category. If $\mathbf{S}\left[\ldots \mathbf{e . . . ]}\right.$ and $\mathbf{S}\left[\ldots \mathbf{e}^{\prime} . ..\right]$ are sentences free of quotation contexts and $\mathbf{S}[. . . \mathbf{e . . .}]$ is the result of substituting $\mathbf{e}$ in for an occurrence of $\mathbf{e}^{\mathbf{\prime}}$ in the sentence $\mathbf{S}\left[\ldots \mathbf{e}^{\prime} . ..\right]$, then if $\mathbf{e}$ and $\mathbf{e}^{\prime}$ are synonymous, then $\mathbf{S}[\ldots . . . .$.$] and \mathbf{S}\left[. . . \mathbf{e}^{\prime}\right.$... $]$ mean the same.

P3 The sentences:

$\mathrm{S} 1$ Hesperus is visible in the evening.

$\mathrm{S} 2$ Phosphorus is visible in the evening.

differ only in the substitution of Phosphorus for an occurrence of Hesperus.

P4 If Hesperus and Phosphorus are synonymous, then S1 and S2 mean the same. From P5 \& Compositionality

P5 If S1 and S2 mean the same, then if a competent speaker possesses sufficient evidence in a context $\mathrm{c}$ to accept $\mathrm{S} 1$, then that speaker possesses sufficient evidence in c to accept S2 as well. ${ }^{7}$

P6 Competent speakers possess sufficient evidence in c to accept S1.

P7 Competent speakers lack sufficient evidence in c to accept S2.

P8 S1 and S2 do not mean the same. From P5, P6 \& P7 by modus tollens

This premise represents but one way of formulating Frege's puzzle. There are a number of other premises that may be deployed instead. For an illuminating discussion of the relations between these premises and the resulting versions of Frege's puzzle see Thau (2002). 
P9 Hesperus and Phosphorus are nonsynonymous. From P4 \& P8 by modus tollens

P10 Hesperus and Phosphorus denote the same object. Empirical premise

C The meaning of a name is not the object that it denotes. From P1, P9 \& P10 by modus tollens

There are some striking parallels between OQA and FP. Both have as their targets claims about a difference in meaning. Whereas OQA purports to establish that moral and descriptive predicates are nonsynonymous, FP purports to establish that some codenoting names are nonsynonymous. Not only do these arguments purport to establish a difference in meaning, but they also deploy essentially the same premises. Both OQA and FP involve compositionality as a premise. Moreover, each involves as a premise a principle linking an epistemic feature of a sentence with its meaning. Thus, Moore assumes that if two questions mean the same, then if a competent speaker's understanding of one question constitutes insufficient evidence to know its answer, then his understanding of the other constitutes insufficient evidence to know its answer. Likewise, Frege assumes that if two sentences mean the same, then if a competent speaker possesses sufficient evidence to accept one sentence, then he possesses sufficient evidence to accept the other. Moreover, given certain meaning platonist assumptions, each of these principles are universal instantiations of Leibniz's law, the indiscernability of identicals:

For all $\mathrm{x}$ and $\mathrm{y}$, if $\mathrm{x}=\mathrm{y}$, then for all properties $\mathrm{p}$, if $\mathrm{p}$ is property of $\mathrm{x}$, then $\mathrm{p}$ is a property of $\mathrm{y} .^{8}$

Suppose that there are propositions and that the meaning of a context insensitive sentence is the proposition that it expresses. Suppose further that evidence is always evidence for the truth (or falsity) of some proposition-that evidentiary relations obtain primarily among propositions and only derivatively among the sentences that convey them. Suppose as well that in accepting a sentence a competent speaker believes the proposition conveyed by that sentence in the context of utterance. And suppose that, at least in this instance, the proposition expressed is conveyed by the relevant utterance. Given these assumptions, the Fregean premise that if two sentences mean the same, then the evidence for the acceptance of one sentence is evidence for the 
acceptance of the other is a universal instantiation of Leibniz's law (Salmon, 1986, 57). ${ }^{9}$ Specifically:

If the proposition expressed by $\mathrm{S} 1$ = the proposition expressed by $\mathrm{S} 2$, then if the ancient astronomers possessing sufficient evidence to believe it is a property of the proposition expressed by $\mathrm{S} 1$, then the ancient astronomers possessing sufficient evidence to believe it is a property of the proposition expressed by $\mathrm{S} 2$.

The same is true of the Moorean premise. Suppose that there are propositions and that the meaning of a context insensitive question is the proposition that it expresses. Suppose further that openness is primarily a feature of propositions and only derivatively a feature of the questions that convey them. And suppose that, at least in this instance, the proposition expressed is conveyed by the relevant utterance. Given these assumptions, the Moorean premise that if two questions mean the same, then if one question is open then the other question is open is itself a universal instantiation of Leibniz's law. Specifically:

If the proposition expressed by Q1 = the proposition expressed by $\mathrm{Q} 2$, then if being open is a property of the proposition expressed by $\mathrm{Q} 1$, then being open is a property of the proposition expressed by Q2.

Whereas there is as of yet no consensus concerning the soundness of FP, there is widespread (if not universal) agreement that OQA is unsound. ${ }^{10}$ One orthodox line of reasoning behind this verdict can be reconstructed as follows. If OQA were sound, then the following semantic principle would be true:

\section{Predicate Transparency}

If it is possible for competent speakers to understand predicates $\mathbf{F}$ and $\mathbf{G}$ without thereby possessing sufficient evidence to know that they apply to the same range of things, then $\mathbf{F}$ and $\mathbf{G}$ are nonsynonymous.

This principle, however, is false. Consider Kripke's (1979/1988, p. 134) example: Furze and gorse are normally regarded as synonyms. Indeed, even Austin, who once entertained the hypothesis that there are no synonyms in

9 Though this is a common way of talking, it has not gone unquestioned. Thus Cartwright (1971) has argued that Leibniz's law should not be understood as a general principle from which such instances may be derived; rather, there are a plurality of distinct indiscernability principles all of which are on a par. This would be fine with me if it were so. open question argument in one form or another. 
English, conceded that furze and gorse are synonymous and modified his hypothesis accordingly - there are no synonyms in English except furze and gorse. However, it is possible for a competent speaker of English to learn furze and gorse normally, such that he perfectly understands these expressions, and on separate occasions, and yet coherently wonder whether they denote the same species or merely similar species. Such a speaker would understand the expressions, furze and gorse, and not thereby know that they apply to the same range of things, but furze and gorse are synonymous nonetheless. Indeed, there are many examples in the literature of synonymous expressions where it is possible for competent speakers to understand them and yet fail to know that they are coextensive. ${ }^{11}$ Moreover, not all of these examples involve natural kinds. Salmon (1989) argues that a competent speaker of English could learn ketchup and catsup normally and separately and yet coherently wonder whether they denote the same or merely similar sauces. The meaning of an expression is not fully transparent to a competent speaker that understands it. And insofar as OQA, if sound, implies otherwise (at least for predicates), we should reject that argument as unsound.

This is something like the orthodox reasoning behind the verdict that OQA is unsound. ${ }^{12}$ While there is widespread (if not universal) agreement concerning the unsoundness of OQA, the likely unsoundness of FP is more controversial. This should be puzzling. If I am right that OQA is a variant of FP, then whatever reason there is to doubt the soundness of the former is reason to doubt the soundness of the latter. Indeed, parallel reasoning would constitute a defense of Millianism. Consider the corresponding thesis about names:

\section{Name Transparency}

If it is possible for competent speakers to understand names $\mathbf{a}$ and $\mathbf{b}$ without thereby possessing sufficient evidence to know that they denote the same object, then $\mathbf{a}$ and $\mathbf{b}$ are nonsynonymous.

Let $\mathbf{S}[. . . \mathbf{b} . .$.$] be the result of replacing an occurrence of name \mathbf{a}$ in $\mathbf{S}[\ldots \mathbf{a . . .}]$ with name b. If name transparency were false, then it would be plausible that a competent speaker that understands $\mathbf{a}$ and $\mathbf{b}$ could, without irrationality or pragmatic incoherence, accept the sentence $\mathbf{S}[\ldots \mathbf{. . . . .}]$ and reject the sentence S[...b...] even though the names $\mathbf{a}$ and $\mathbf{b}$ mean the same. Thus it would be plausible that a competent speaker that understands Hesperus and Phospho-

11 See, inter alia, Rieber (1992), Salmon (1989, 1990), and Soames (1986). Relevant examples can be found in almost any of the literature on the paradox of analysis and Mates' puzzle.

12 For representative statements of what I have been describing as the orthodox reasoning see Boyd (1988), Putnam (1981, 206-7), and Smith (1986). 
rus could, without irrationality or pragmatic incoherence, accept Hesperus is visible in the evening and reject Phosphorus is visible in the evening even if Hesperus and Phosphorus meant the same. Notice that this, or something very much like it, is the position defended by contemporary Millians. What is puzzling, then, is the readiness of so many to deny the transparency of the meanings of predicates and yet to insist on the transparency of the meanings of names.

It is more than a puzzle in the philosophy of language. The failure to appreciate that OQA is a variant of FP has caused confusion in metaethics. Consider the following example (we will discuss another, closely related example in the next section). Consider, specifically, the following form of Fregean naturalist. His naturalism consists in the claim that moral predicates denote natural properties; ${ }^{13}$ indeed, they are codenoting with certain (complex) natural predicates. His Fregeanism consists in the denial that moral predicates are synonymous with any natural predicate. So, a moral predicate differs in meaning from every natural predicate-even from the codenoting natural predicate. (Compare Fregean naturalism to a widely accepted view about the meaning and denotation of natural kind terms: Water and $\mathbf{H}_{2} \mathbf{O}$ differ in meaning despite denoting the same natural kind.) One cannot coherently endorse Fregean naturalism and accept the orthodox verdict concerning OQA: Doing so would undermine one's reason for denying that a moral predicate is synonymous with the codenoting natural predicate. But the leading exponents of the orthodox verdict, Boyd (1988), Putnam (1981), and Smith (1986) are Fregean naturalists.

I have claimed that if OQA and FP were sound, then the semantic principles, predicate and name transparency, would be true. Moreover, I have suggested that these principles are false. At most such considerations would establish that there is reason to doubt the soundness of OQA and FP. They do not, however, fully establish the unsoundness of OQA and FP. To fully establish their unsoundness, one needs to explain what is wrong with these arguments. Establishing that OQA and FP are unsound involves explaining, if they are invalid, why they are invalid; and explaining, if some of their premises are false, which of their premises are false. But these explanations have not been given. Moreover, the explanation of the unsoundness of OQA and FP should be linked to the explanation of the failures of predicate and name transparency. The present objection crucially turns on the thought that if OQA and FP are sound then predicate and name transparency are true. So an explanation of the unsoundness of OQA and FP should be the basis of an explanation for the failures of predicate and name transparency. And again, these latter explanations have not been given. While we have the beginnings

13 Natural properties are a subkind of descriptive properties and contrast with supernatural properties. 
of a case against OQA and FP, the full case has yet to be given. We will be in a better position to appreciate the unsoundness of OQA and FP and the failures of predicate and name transparency as the discussion proceeds. The explanation of the unsoundness of OQA and FP will be given in section six. The explanation of the failures of predicate and name transparency will be given in section seven.

\section{Moore's Case for Nonnaturalism}

OQA purports to reveal something about the metaphysics of morals, but, strictly speaking, the immediate conclusion of the argument is that no moral predicate is synonymous with any descriptive predicate. On this basis, Moore argues that moral properties are distinct from descriptive properties and so differ in kind.

I have criticized OQA for its commitment to predicate transparency-for involving the controversial assumption that anyone who understands two synonymous predicates would thereby possess sufficient evidence to know that they apply to the same range of things. But a more telling criticism is that the metaphysical conclusion that Moore draws simply does not follow from the claim that moral predicates are nonsynonymous with descriptive predicates.

Consider, then, Moore's case for nonnaturalism. The case for nonnaturalism has a positive and a negative component. According to nonnaturalism, there are moral properties and no moral property is identical to any descriptive property. Since there are moral properties and none are identical to any descriptive property, moral properties must differ in kind from descriptive properties - they must be nonnatural properties. It is important to recognize the positive component of nonnaturalism. Someone might accept the claim that no moral property is identical to any descriptive property for the trivial reason that there are no moral properties. But nonnaturalism is not a species of nonfactualism. The conclusion of OQA is supposed to form the basis of an argument for the negative component of nonnaturalism - that moral properties are distinct from natural (or descriptive) properties. But how does Moore move from the premise:

No moral predicate is synonymous with any descriptive predicate.

to the conclusion:

No moral property is identical to any descriptive property.

The argument is invalid as it stands. For all that has been said, goodness might be a descriptive property even though good is nonsynonymous with any descriptive predicate. Compare: George W. Bush is the president of the 
United States even though George W. Bush and the president of the United States differ in meaning.

According to the standard objection, in order to construct a valid argument, Moore needs an extra premise linking predicate synonymy with property identity:

If predicates $\mathbf{F}$ and $\mathbf{G}$ denote the same property, then $\mathbf{F}$ and $\mathbf{G}$ are synonymous.

But, the objection continues, this principle embodies a view of properties now widely regarded as false. ${ }^{14}$ According to predicate nominalism, whenever we have a meaningful predicate $\mathbf{F}$ we may harmlessly speak of the property of being $\mathrm{F} .{ }^{15}$ The transition is supposed to be as unproblematic as our unreflective transition from It is true that $\mathbf{S}$ to $\mathbf{I t}$ is a fact that $\mathbf{S}$. Indeed, the transition is underwritten by an a priori comprehension scheme-an a priori specification of the existence of properties in terms of the meanings of predicates. Moreover, according to predicate nominalism, properties are individuated by an equivalence relation on predicates. Specifically, two predicates will denote the same property just in case they are synonymous. Indeed, this is underwritten by an a priori abstraction principle-an a priori specification of the identities of properties in terms of the equivalence relation of synonymy on predicates. So according to predicate nominalism, the existence and identity of properties is explained in terms of the meanings of predicates:

\section{Predicate Nominalism}

1 It is a priori that: The property of being $\mathbf{F}$ exists iff $\mathbf{F}$ is a meaningful predicate.

2 It is a priori that: The property of being $\mathrm{F}=$ the property of being $\mathrm{G}$ iff $\mathbf{F}$ and $\mathbf{G}$ are synonymous.

Predicate nominalism, however, faces a number of difficulties. According to predicate nominalism, there will be at least as many properties as there are predicates, but given the inevitable expressive limitations of language, the number of properties must surely outstrip the number of available predicates. ${ }^{16}$ Worse still, the comprehension scheme is incoherent. Consider the

14 See, inter alia, Brink (1989, ch. 6), and Horgan and Timmons (1992).

15 The terminology is Armstrong's (1980).

16 How the predicate nominalist can account for this is a difficult matter. He could either formulate the comprehension scheme in terms of possible predicates or in terms of transcendent predicate types (transcendent types exist whether or not they have tokens). Thus the predicate nominalist could claim that for every possible meaningful predicate there will be a property or that for every (potentially meaningful) transcendent predicate type there will be a corresponding property. As for the former option, one may well 
predicate non-self-instantiating. Is the property of being non-self-instantiating itself non-self-instantiating? If the predicate nominalist does not suitably restrict the transition from meaningful predicates to properties then a variant of Russell's paradox threatens. But once one imposes the relevant restrictions on the comprehension scheme, predicate nominalism begins to be less deliberately naïve and more controversial. Indeed if type restrictions were imposed it would be a notational variant of Russell's theory of propositional functions. For these and related reasons predicate nominalism is now widely regarded as false. And if the needed missing premise-that if two predicates denote the same property, then they are synonymous-presupposes predicate nominalism, then the resulting argument is unsound.

Unfortunately, the standard objection is off target. Moore's argument does not presuppose predicate nominalism, it presupposes:

\section{Predicate Millianism}

1 The meaning of a predicate $\mathbf{F}$ exists iff $\mathbf{F}$ denotes a property.

2 The meaning of a predicate $\mathbf{F}=$ the meaning of a predicate $\mathbf{G}$ iff $\mathbf{F}$ and $\mathbf{G}$ are codenoting.

Predicate Millianism entails the missing premise-after all, if there is nothing more to the meaning of a predicate than the property it denotes, then if two predicates denote the same property, then they are synonymous. Moreover, predicate nominalists are committed to predicate Millianism. If the existence and identity of properties a priori depends on the existence and identity of predicate meanings, then no matter how finely predicate meanings are individuated, denoted properties will be individuated just as finely. That means that there could be no codenoting predicates that differ in meaning. But one can be a predicate Millian without being a predicate nominalist. A predicate Millian can consistently deny that the existence and identity of properties $a$ priori depends on the existence and identity of predicate meanings. And if a predicate Millian were to do so, then far from explaining properties in terms of predicate meanings, he would be explaining predicate meanings in terms of properties. The standard objection is wrong. The missing premise presupposes, not predicate nominalism, but predicate Millianism. So the likely falsity of predicate nominalism does nothing to cast doubt on the truth of the missing premise.

wonder whether the notion of a possible predicate is any clearer than the notion of a property that it purports to explicate. The latter option, however, is especially uncongenial since types (whether of expressions or not) are properties and are thus precisely what the predicate nominalist seeks to account for. 
While the standard objection fails, the fact that the argument presupposes predicate Millianism highlights an important difficulty that we have overlooked so far. No one could coherently accept OQA as sound and reason from the nonsynonymy of predicates to the distinctness of the properties they denote. In the last section I argued that OQA is a variant of FP. But if OQA is a variant of FP, then OQA is at least the basis of an argument for there being more to the meaning of a predicate than the property it denotes. ${ }^{17}$ According to the Fregean, two predicates can denote the same property and yet differ in meaning. But if codenoting predicates can differ in meaning, there is no valid argument from the nonsynonymy of predicates to the distinctness of the properties they denote. Just because $\operatorname{good}$ and $\mathbf{F}$ differ in meaning it would not follow that they differ in denotation. Good and F might denote the same descriptive property despite differing in meaning (by denoting the same property under distinct modes of presentations). So if OQA is a variant of FP, then no one who accepts the soundness of OQA could coherently reason from moral predicates being nonsynonymous with descriptive predicates to their differing in denotation. If Moore really did reason from the conclusion of OQA to the negative component of nonnaturalism, then by his own lights, this argument fails. ${ }^{18}$

\section{Nonreductive Descriptivism and Nonnaturalism}

There is a further problem. Forget, for a moment, that the argument for nonaturalism and OQA are part of the same package. Consider the argument for the negative component of nonnaturalism in isolation from OQA. Even if we assume predicate Millianism, the argument that moral properties are distinct from descriptive properties fails. By contraposition the missing premise is equivalent to:

17 Predicate Fregeanism is motivated by a reductio of predicate Millianism. Furze and gorse denote the same species. If predicate Millianism were true, then furze and gorse must mean the same. But the Fregean believes (pace Austin!) that we can decisively establish that furze and gorse are not synonyms. Suppose the predicates furze and gorse were indeed synonymous. If furze meant just the same as gorse, then we could always replace one with the other in any sentence without changing that sentence's meaning. So the question:

Granted that $\mathrm{x}$ is a furze, is $\mathrm{x}$ a gorse?

would mean just the same as the question:

Granted that $\mathrm{x}$ is a furze, is $\mathrm{x}$ a furze?

But whereas it is perfectly intelligible to ask the former question, it is absurd to ask the latter. So these two questions do not mean the same, and thus furze is nonsynonymous with gorse. Since furze and gorse are nonsynonymous despite denoting the same species, the meaning of a predicate is not the property it denotes.

This suggests that it is perhaps a mistake to attribute to Moore the metalinguistic version of the open question argument. In section four, we will consider a reformulation of the open question argument in terms of Leibniz's law. 
If $\mathbf{F}$ and $\mathbf{G}$ are nonsynonymous, then $\mathbf{F}$ and $\mathbf{G}$ denote distinct properties.

But from this and the premise:

No moral predicate is synonymous with any descriptive predicate.

all we are entitled to conclude is:

No property denoted by a moral predicate is identical to any property denoted by a descriptive predicate.

But the negative component of nonnaturalism is a different claim:

No moral property is identical to any descriptive property.

From the mere fact that distinct kinds of predicates differ in denotation, it does not follow that the denoted properties themselves differ in kind. Indeed, the contrary supposition involves a kind of use/mention mistake: It mistakes a claim about representations (that distinct kinds of predicates differ in denotation) for a claim about what they represent (that the distinct denoted properties themselves differ in kind).

The present objection turns on the logical possibility of nonreductive descriptivism - of normative predicates denoting descriptive properties not denoted by any descriptive predicate. The thought is that one could discover that a normative predicate denotes a descriptive property not by identifying the property it denotes with the denotation of a descriptive predicate, but by simply discovering that the property it denotes is descriptive. But is this logical possibility metaphysically possible?

Perhaps, not. Nonreductive descriptivism presupposes that the metaphysical distinction between normative and descriptive properties is understood independently of the linguistic distinction between normative and descriptive predicates. After all, if a normative predicate can denote a descriptive property not denoted by any descriptive predicate, then the notion of a descriptive property must be understood independently of descriptive predicates. But while we have some idea of what the higher-order properties of normative properties might be, we have no idea what the higher-order properties of descriptive properties are. (Unless, of course, descriptive just means nonnormative.) And if we have no idea what the higher-order properties of descriptive properties are, then how could we ever discover that the denotation of a normative predicate is a descriptive property ${ }^{19}$

19 That we lack a positive conception of descriptive properties can be masked by conflating two senses of natural. Most contemporary descriptivists are naturalists. Recall (note thirteen), natural properties are a subclass of descriptive properties and contrast with super- 
Notice that this is not just a problem for nonreductive descriptivism. It is equally a problem for the nonnaturalist. The nonnaturalist claims that normative properties differ in kind from descriptive properties. But if we have no idea what the higher-order properties of descriptive properties are, then we have no idea of the content of this denial. We would not know what normative properties differ in kind from. Unless we have some positive conception of what descriptive properties are, the distinction between nonreductive descriptivism and nonnaturalism collapses.

Perhaps these difficulties tell against the assumption that the metaphysical distinction between normative and descriptive properties is basic. There are two possible relationships between the metaphysical and linguistic distinctions. On the one hand, one could take the metaphysical distinction as basic and explain the linguistic distinction in terms of it. Thus, one might claim that a predicate is normative because it denotes a normative property; and that a predicate is descriptive because it denotes a descriptive property. On the other hand, one might take the linguistic distinction as basic and explain the metaphysical distinction in terms of it. Thus, one might claim that a property is normative because a normative predicate denotes it; and that a property is descriptive because a descriptive predicate denotes it. Notice if we instead took the linguistic distinction as basic, then we would have the basis of a valid argument for the negative component of nonnaturalism. If a property is descriptive because a descriptive predicate denotes it, then establishing that no normative predicate is codesignative with any descriptive predicate is sufficient to establish that no normative predicate denotes a descriptive property. And since normative properties just are the properties denoted by normative predicates, it would follow that no normative property is identical with any descriptive property.

Unfortunately, taking the linguistic distinction as basic would result in too quick an argument for the negative component of nonnaturalism. Indeed Moore's argument would be unnecessary. If a property is normative or descriptive because it is denoted by a normative or a descriptive predicate, then a property is only normative or descriptive if it is denoted by a normative or a descriptive predicate. But as the distinction between normative and descriptive predicates constitutes a partition, it would follow that the distinction between normative and descriptive properties would itself constitute a

natural properties. Normative naturalism claims that normative properties are themselves a subkind of natural properties. But there is a distinct sense of naturalism that is a form of scientism. According to this latter sense, natural properties are the properties postulated by (or explained in terms of) the natural sciences. We have some idea what the higherorder properties of natural properties in this latter sense are. (But see Crane and Mellor, 1990.) So, if we are not careful to distinguish these senses of natural, this fact can mislead us into thinking that we have some idea what the higher-order properties of natural properties in the former sense are (apart from being nonsupernatural). 
partition. But that would rule out in advance the possibility of moral descriptivism.

\section{The Open Question Argument and Leibniz's Law}

The difficulties with OQA are due to the fact that the argument is explicitly metalinguistic. The immediate conclusion of the argument is that no moral predicate is synonymous with any descriptive predicate. And it is precisely this feature of Moore's argument that was the source of our difficulties. For, so formulated, the argument relies on a controversial semantic principle-that any competent speaker that understands two synonymous predicates would thereby possess sufficient evidence to know that they apply to the same range of things. Moreover, as we have seen, there is no direct entailment from moral predicates being nonsynonymous with descriptive predicates to Moore's metaphysical conclusion. But does not Moore himself insist on the irrelevance of verbal definition to moral philosophy? And does he not do so, in part, because verbal definitions have a linguistic subject matter whereas analytic definitions concern the nature of the property in question? This suggests that it was, perhaps, a mistake to attribute to Moore a metalinguistic formulation of the open question argument. ${ }^{20}$

Perhaps, then, the open question argument should be formulated, not in terms of compositionality, but, rather, in terms of Leibniz's law, the indiscernibility of identicals:

For all $\mathrm{x}$ and $\mathrm{y}$, if $\mathrm{x}=\mathrm{y}$, then for all properties $\mathrm{p}$, if $\mathrm{p}$ is a property of $x$, then $p$ is a property of $y$.

So formulated, the argument would have the advantage of being directly about the properties in question rather than being about their linguistic surrogates-the predicates that denote them. ${ }^{21}$

Recall the problem in distinguishing nonreductive descriptivism from nonnaturalism was due to our lacking a positive conception of what descriptive properties are. If we have no idea what the higher-order properties of descriptive properties are, then we have no way of deciding whether normative properties are distinct in kind from descriptive properties or are merely a distinct subkind of descriptive property. If this is an approximately correct description of our epistemic situation, then it is an exaggeration to say that we don't know any of the higher-order properties of descriptive properties.

20 Though perhaps only on the assumption that Moore's explicit recognition that it is a mistake to confuse use with mention is evidence that he is not disposed to make this mistake. This assumption is questionable. One can explicitly recognize that it is a mistake not to bend one's knees when swinging a gold club and yet still be disposed to swing stiffkneed. But why should bad intellectual habits be any different from bad physical habits? can only be reconstructed in terms of Leibniz's law. 
Descriptive properties would have certain epistemic, higher-order properties. Specifically, descriptive properties would have the higher-order property of it being an open question whether any descriptive property is normative. The reformulation of the open question argument in terms of Leibniz's law crucially exploits this kind of epistemic, higher-order property:

The Reformulated Open Question Argument $O Q A_{L L}$

\section{P1 Leibniz's law}

For all $\mathrm{x}$ and $\mathrm{y}$, if $\mathrm{x}=\mathrm{y}$, then for all properties $\mathrm{p}$, if $\mathrm{p}$ is a property of $x$, then $p$ is a property of $y$.

P2 If $\mathrm{F}$-ness $=$ goodness, then for all properties $\mathrm{p}$, if $\mathrm{p}$ is a property of F-ness, then $\mathrm{p}$ is a property of goodness. From Leibniz's law by universal instantiation

P3 F-ness has the higher-order property that it is an open question whether everything that instantiates it is good.

P4 Goodness does not have the higher-order property that it is an open question whether everything that instantiates it is good.

C F-ness $\neq$ goodness. From P2-P4 by modus tollens

Just like the prior reconstruction, $\mathrm{OQA}_{\mathrm{LL}}$ is perfectly general. If it is a sound argument that goodness is not identical to some particular descriptive property (such as being what we desire to desire) then it is the basis of a sound argument that goodness is not identical to any descriptive property. One need only run the argument for every descriptive property. $\mathrm{OQA}_{\mathrm{LL}}$ is general in another way as well. If it is the basis of a sound argument that goodness is not identical to any descriptive property, it is the basis of a sound argument that no moral property is identical to any descriptive property. One need only run the argument for every moral property and every descriptive property. Given this, $\mathrm{OQA}_{\mathrm{LL}}$ is a direct argument for the negative component of nonnaturalism - that no moral property is identical to any descriptive property. Since $\mathrm{OQA}_{\mathrm{LL}}$ provides a direct argument for the negative component of nonnaturalism, it avoids the difficulties of trying to establish this metaphysical conclusion on the basis of semantic premises. As such, OQA $\mathrm{LL}_{\mathrm{L}}$ might appear to be a better argument than the original reconstruction. But is it sound?

One might object to $\mathrm{OQA}_{\mathrm{LL}}$ that it is an instance of the familiar failure of Leibniz's law. Consider the analogous argument that Arnauld (1641/1984) attributes to Descartes: 
P1 Leibniz's law

For all $\mathrm{x}$ and $\mathrm{y}$, if $\mathrm{x}=\mathrm{y}$, then for all properties $\mathrm{p}$, if $\mathrm{p}$ is a property of $x$, then $p$ is a property of $y$.

P2 If my body $=$ my mind, then for all properties $\mathrm{p}$, if $\mathrm{p}$ is a property of my body, then $\mathrm{p}$ is a property of my mind. From Leibniz's law by universal instantiation

P3 Being doubtful is a property of my body.

P4 Being doubtful is not a property of my mind.

C My body $\neq$ my mind. From P2-P4 by modus tollens

This argument is obviously unsound. And some have been tempted to attribute the unsoundness of this argument to the illicit application of Leibniz's law. Specifically, it is sometimes maintained that Leibniz's law should be restricted to nonintensional properties. ${ }^{22}$ According to this line of objection, the unrestricted version of Leibniz's law as it occurs in P3 is false, and, hence, the argument is unsound. But if we reformulate Leibniz's law with the operative restriction:

For all $\mathrm{x}$ and $\mathrm{y}$, if $\mathrm{x}=\mathrm{y}$, then for all nonintensional properties $\mathrm{p}$, if $\mathrm{p}$ is a property of $\mathrm{x}$, then $\mathrm{p}$ is a property of $\mathrm{y}$.

the resulting argument is invalid, since the property of being doubtful is an intensional property. If that's right, then $\mathrm{OQA}_{\mathrm{LL}}$ is unsound as well since it involves as a premise the unrestricted version of Leibniz's law. But if OQA $A_{L L}$ is formulated in terms of the restricted version of Leibniz's law, then it is invalid. Just as the property of being doubtful is an intensional property, so is the higher-order property of being an open question whether everything that instantiates it is good.

This is a tissue of confusion. First of all, it is unclear how even to give content to the restricted version of Leibniz's law. After all what could an

22 The alleged failures of Leibniz's law purport to establish its intensionality. But the intensionality of Leibniz's law is certainly not due to its being explicitly formulated in intensional idiom. Leibniz's law is formulated in the idiom of first-order logic and that is extensional if anything is. Rather, the alleged intensionality of Leibniz's law derives from its quantifiers purportedly ranging over special intensional entities-intensional properties. This is a generalization of the explanation of the intensionality of modality in terms of quantification over intensional entities-in this case, possible worlds. Subsequent discussion suggests that this pattern of explanation is bankrupt. 
intensional property be if not a property that would violate Leibniz's law. But if that's what an intensional property is, then restricting Leibniz's law to nonintensional properties is devoid of content. One cannot both characterize an intensional property as a property that would falsify the unrestricted version of Leibniz's law and formulate Leibniz's law in terms of a restriction to nonintensional properties. That's like saying that this principle is true of all properties except those properties that would falsify this principle. But if intensional properties cannot be characterized as properties that would violate Leibniz's law, how else are they to be characterized? It is utterly unclear what, in this context, an intensional property could be. We will return to this issue later.

Even if content could be given to the restricted version of Leibniz's law, there is still a problem. The present objection is motivated, in no small part, by what is taken to be the standard Fregean response to Frege's puzzle. But the standard Fregean response does not support the claim that there are failures of Leibniz's law. If anything, the standard Fregean response is a vindication of Leibniz's law in the face of its apparent failure.

Earlier, I noted that the OQA is analogous to FP. There is a further analogy that is presently relevant, namely, that each admits of a variant formulation in terms of Leibniz's law. Specifically, Frege's puzzle can be formulated as follows:

Frege's Puzzle Reformulated FP $P_{L L}$

\section{P1 Leibniz's law}

For all $\mathrm{x}$ and $\mathrm{y}$, if $\mathrm{x}=\mathrm{y}$, then for all properties $\mathrm{p}$, if $\mathrm{p}$ is a property of $x$, then $p$ is a property of $y$.

P2 If Hesperus $=$ Phosphorus, then for all properties $\mathrm{p}$, if $\mathrm{p}$ is a property of Hesperus, then $\mathrm{p}$ is a property of Phosphorus. From Leibniz's law by universal instantiation

P3 Hesperus has the property that the ancient astronomers believed that it is visible in the evening.

P4 Phosphorus does not have the property that the ancient astronomers believed that it is visible in the evening.

C $\quad$ Hesperus $\neq$ Phosphorus. From P2-P4 by modus tollens ${ }^{23}$

23 There is, however, an important disanlogy between $\mathrm{OQA}_{\mathrm{LL}}$ and $\mathrm{FP}_{\mathrm{LL}}$. Whereas, it is possible to accept $\mathrm{OQA}_{\mathrm{LL}}$ as sound it is not possible to accept $\mathrm{FP}_{\mathrm{LL}}$ as sound. $\mathrm{FP}_{\mathrm{LL}}$ is after all an argument to the incredible conclusion that Venus is not identical to itself. The anal- 
The relevant transitions are apparently valid, but we are led by means of them to the incredible conclusion that Venus is not identical to itself. We have a puzzle, and apparently the only way out of it is to deny one of the premises. Initially it might appear that Leibniz's law is the culprit. But the standard Fregean response to this puzzle is not to deny this premise. Indeed, in order to vindicate Leibniz's law in the face of its apparent failure, they postulate a range of special entities, modes of presentations, and argue that what reflection on the puzzle establishes is not that Venus is distinct from itself; but, rather, that there are distinct modes of presentations of Venus. ${ }^{24}$ Strictly speaking, the ancient astronomers belief did not ascribe a property, being visible in the evening, to an object Venus; rather, their belief ascribes a property to Venus under a mode of presentation. The ancient astronomers believed of Venus under a particular mode of presentation $\mathrm{MP}_{\text {Hesperus }}$ that it visible in the evening, and it is only under a distinct mode of presentation $\mathrm{MP}_{\text {Phosphorus }}$ that the ancient astronomers failed to believe that Venus is visible in the evening. Moreover, the only reason for maintaining that the relevant modes of presentation are distinct is via an application of Leibniz's law. Specifically, there is a mode of presentation $\mathrm{MP}_{\mathrm{Hesperus}}$ that has the property that under it the ancient astronomers believed of Venus that it is visible in the evening. There is a mode of presentation $\mathrm{MP}_{\text {Phosphorus }}$ that does not have the property that under it the ancient astronomers believed of Venus that it is visible in the evening. Given Leibniz's law, it follows that $\mathrm{MP}_{\text {Hesperus }}$ and $\mathrm{MP}_{\text {Phosphorus }}$ are distinct modes of presentation of Venus.

I suspect that the conviction that the standard Fregean response shows that there are failures of Leibniz's law is due to a conflation. Specifically, Leibniz's law:

For all $\mathrm{x}$ and $\mathrm{y}$, if $\mathrm{x}=\mathrm{y}$, then for all properties $\mathrm{p}$, if $\mathrm{p}$ is a property of $x$, then $p$ is a property of $y$.

is conflated with a superficially similar principle:

\section{Substitutivity}

All instances of the scheme:

$$
\text { If } x=y, \text { then if } S[\ldots x \ldots] \text { then } S[\ldots y \ldots]
$$

ogy would restored if we had considered, instead, an argument to the conclusion that the belief that Hesperus is visible in the evening is distinct from the belief that Phosphorus is visible in the evening.

24 There is an analogy with Frege's response to the puzzle formulated in terms of compositionality. Notice that Leibniz's law plays the role compositionality plays in the original formulation of the puzzle. And Frege himself is explicit that the postulation of modes of presentations is required to vindicate compositonality in the face of apparent counterexamples to that principle. For useful discussion see Burge (1986). 
are true (where $\mathbf{x}$ and $\mathbf{y}$ are schematic letter whose permissible substituends are names and the sentential matrices, $\mathbf{S}[\ldots \mathbf{. . . .}]$ and $\mathbf{S}[\ldots \mathbf{. . . .}]$, are free from quotation contexts).

At first glance, substitutivity can seem to be a notational variant of Leibniz's law, at least given certain idealizations. Suppose that every object has a name, and every property a (possibly complex) predicate, that there are no empty names or predicates, and no context sensitivity. Whereas Leibniz's law is formulated in the material mode, substitutivity is formulated in the formal mode. And given our assumptions, they can seem to be equivalent.

But whereas the former principle is incontrovertible - the indiscernibility of identicals is, after all, plausibly constitutive of both the identity relation and being a property - the latter principle is controversial. Notice the latter principle licenses the substitution of codesignative singular terms salva veritate-even in propositional attitude constructions. ${ }^{25}$ And what the standard Fregean response casts doubt on is precisely this. For suppose that associated with competent speakers' use of the name Hesperus is a mode of presentation, $\mathrm{MP}_{\text {Hesperus, }}$ and associated with competent speakers' use of the name Phosphorus is a distinct mode of presentation, $\mathrm{MP}_{\text {Phosphorus }}$. Suppose further that the ancient astronomers believed of Venus under $\mathrm{MP}_{\text {Hesperus }}$ that it is visible in the evening but failed to believe of Venus under $\mathrm{MP}_{\text {Phosphorus }}$ that it is visible in the evening. Suppose further that the truth of a belief ascription is sensitive to the modes of presentations associated with the names used in the that-clause. Then the following instance of substitutivity:

If Hesperus $=$ Phosphorus, then if the ancient astronomers believed that Hesperus is visible in the evening, then the ancient astronomers believed that Phosphorus is visible in the evening.

is false. What the standard Fregean response casts doubt on is not Leibniz's law but substitutivity. And it is only by unwittingly vacillating between the two that one could think otherwise. ${ }^{26}$

The distinction between Leibniz's law and substitutivity is relevant, as well, to the characterization of intensional properties. Given substitutivity, we can characterize a notion of an intensional predicate. Specifically, an intensional predicate is any sentential matrix that occurs in a false instance of substitutivity. Potential examples of intensional predicates include: is doubtful, is an open question whether everything that has it is good,

\footnotetext{
25 Substitutivity should thus be distinguished from compositionality. Whereas substitutivity licenses the substitution of codesignative names salva veritate, compositionality licenses the substitution of synonymous expressions salva significatione.

26 Cartwright (1971/1987) makes this point. For useful related discussion see Richard (1990, ch. 4.1), and Salmon (1986, ch. 4).
} 
etc. An intensional property can then be characterized as a property denoted by an intensional predicate.

We are now in a position to see clearly the precise confusion involved in the suggestion that Leibniz's law should be retricted to intensional properties. It is only by mistaking substitutivity for Leibniz's law that one is led to believe that there are failures of Leibniz's law. But in proposing a nontrivial restriction on Leibniz's law (specifically, that the principle should be restricted to intensional properties), an intensional property cannot be characterized as a property that violates Leibniz's law. Rather, it must be understood as a property denoted by an intensional predicate where intensional predicates are characterized in terms of the failure of the (implicitly, distinct) principle, substitutivity. The apparent plausibility of the suggestion depends on the impossible-that Leibniz's law and substitutivity are simultaneously the same, yet distinct.

Substitutivity is a principle formulated in the formal mode-it is a metalinguistic principle. Leibniz's law is a principle formulated in the material mode-it is an objectual principle. Mistaking substitutivity for Leibniz's law is a kind of use/mention mistake-involving, as it does, mistaking a metalinguistic principle for an objectual principle. More than that, this mistake masks (and perhaps makes possible) an important de re/de dicto conflation. Notice that false instances of substitutivity such as:

If Hesperus $=$ Phosphorus, then if the ancient astronomers believed that Hesperus is visible in the evening, then the ancient astronomers believed that Phosphorus is visible in the evening.

are de dicto claims. In contrast, the corresponding universal instantiations of Leibniz's law such as:

If Hesperus = Phosphorus, then Hesperus has the property that the ancient astronomers believed that it is visible in the evening, then Phosphorus has the property that the ancient astronomers believed that it is visible in the evening.

are de re claims. So in mistaking substitutivity for Leibniz's law, one is led to mistake a false instance of substitutivity for a failure of Leibniz's law; and so to mistake a de dicto claim for a de re claim.

\section{The Real Problem: Mistaking De Dicto Claims for De Re Claims}

The real problem with the $\mathrm{OQA}_{\mathrm{LL}}$ is not that it involves a failure of Leibniz's law. (How could it?) Rather, it provides one with no reason to believe its conclusion - a fact that can be masked by a de re/de dicto confusion. Let me explain. 
Familarly, that-clauses can give rise to de re/de dicto ambiguities. Consider the following: Edgar has released Bernice's rabbit from its pen. Bernice is understandably upset about her missing rabbit. Suppose someone were to utter the following:

Bernice believes that Edgar is a bad person.

This utterance is ambiguous - it might be used to convey one of two propositions. The speaker might be ascribing to Bernice a de re belief about Edgar-that Bernice believes of Edgar that he is a bad person. But suppose it is presupposed in the conversational context that Edgar is the one who released the rabbit but Bernice does not know this. Then the utterance might be used to ascribe a de dicto belief to Bernice-that whoever released her rabbit from its pen is a bad person.

Just as that-clauses can give rise to de re/de dicto ambiguities, so too can whether-clauses. Suppose, instead, that the speaker utters the following:

Bernice wonders whether Edgar is a bad person.

As before, this utterance is ambiguous - it might be used to convey one of two propositions. The speaker might be ascribing a de re attitude to Bernice-that Bernice wonders of Edgar whether he is a bad person. But suppose it is presupposed in the conversational context that Edgar is the one who released the rabbit but Bernice does not know this. Then the utterance might be used to ascribe a de dicto attitude to Bernice-that Bernice wonders whether whoever released her rabbit from its pen is a bad person.

Now consider the following utterance:

It is an open question whether everything that instantiates F-ness is good.

Once again, this utterance is ambiguous-it might be used to convey one of two propositions. The speaker might be making a de re claim-that F-ness is such that it is an open question of it whether everything that instantiates it is good. But the speaker might be making a de dicto claim-that it is an open question whether everything that instantiates F-ness is good.

Recall that the conclusion of $\mathrm{OQA}_{\mathrm{LL}}$ is that F-ness and goodness are distinct properties. The argument purports to establish that they are distinct by claiming that F-ness has a higher-order property that goodness lacks. Specifically, whereas F-ness has the higher-order property that it is an open question whether everything that instantiates it is good, goodness lacks this higherorder property. By Leibniz's law, F-ness and goodness must be distinct properties. 
It should be clear that the premises that F-ness has a higher-order property and that goodness lacks this higher-order property must be de re claims about these properties in order for the argument to be valid. The conclusion, that Fness and goodness are distinct properties, is supposed to follow from these premises and the universal instantiation of Leibniz's law:

If $\mathrm{F}$-ness $=$ goodness, then for all properties $\mathrm{p}$, if $\mathrm{p}$ is a property of F-ness, then $\mathrm{p}$ is a property of goodness.

But this is a de re claim. The universal instantiation claims of F-ness and of goodness that if they are identical, then whatever is a higher-order property of F-ness is a higher-order property of goodness. But as the universal instantiation is a de re claim, the conclusion will only validly follow if the premises themselves are understood as de re claims. Indeed, if there was anything to the thought that Leibniz's law should be restricted to nonintensional properties, it is just the confused recognition of this fact: That the distinctness of two things will not validly follow from Leibniz's law if the relevant property ascriptions are de dicto claims. It is not that the unrestricted version of Leibniz's law is false; rather, only that conclusions about nonidentity only validly follow from Leibniz's law given the relevant de re premises.

But now there is a problem. The most that Moorean reflection could establish is the de dicto claim:

It is an open question whether everything that instantiates F-ness is good.

But what's required for the validity of the argument is the truth of the corresponding de re claim:

F-ness is such that it is an open question of it whether everything that instantiates it is good.

But there is no reason to believe the de re premise without antecedently believing that F-ness is distinct from goodness. After all, if you believe of Fness that it is goodness, then it will not be an open question of F-ness whether everything that instantiates it is good. So, if one is initially agnostic about the conclusion of $\mathrm{OQA}_{\mathrm{LL}}$ - if one is agnostic about F-ness being goodness-one should be agnostic about F-ness being such that it is an open question of it whether everything that instantiates it is good. But if that's right, then $\mathrm{OQA}_{\mathrm{LL}}$ provides no positive reason for believing its conclusion. Any appearance to the contrary is due to mistaking the de dicto claim-that it is an open question whether everything that instantiates F-ness is good-for the corresponding de re claim-that F-ness is such that it is an open question of it whether everything that instantiates it is good. 
The formulation of Frege's puzzle in terms of Leibniz's law, $\mathrm{FP}_{\mathrm{LL}}$, is subject to a similar diagnosis. Recall that the conclusion of $\mathrm{FP}_{\mathrm{LL}}$ is that Hesperus and Phosphorus are distinct objects. The argument purports to establish that they are distinct by claiming that Hesperus has a property that Phosphorus lacks. Specifically, whereas Hesperus has the property that the ancient astronomers believed that it is visible in the evening, Phosphorus lacks this property. By Leibniz's law, Hesperus and Phosphorus must be distinct objects.

It should be clear that the premises that Hesperus has some property and that Phosphorus lacks this property must be de re claims in order for the argument to be valid. The conclusion, that Hesperus and Phosphorus are distinct, is supposed to follow from these premises and the following universal instantiation of Leibniz's law:

If Hesperus $=$ Phosphorus, then for all properties $\mathrm{p}$, if $\mathrm{p}$ is a property of Hesperus, then $\mathrm{p}$ is a property of Phosphorus.

But this is a de re claim. The universal instantiation claims of Hesperus and of Phosphorus that if they are identical, then whatever is a property of Hesperus is a property of Phosphorus. But as the universal instantiation is a de re claim, the conclusion will only validly follow if the premises themselves are understood as de re claims.

But now, as before, there is a problem. The most that reflection on astronomical ignorance could establish is the truth of the de dicto claim:

The ancient astronomers did not believe that Phosphorus is visible in the evening.

But what's required for the validity of the relevant transition is the truth of the corresponding de re claim:

The ancient astronomers did not believe of Phosphorus that it is visible in the evening.

But, it is overwhelmingly plausible that this claim is false. When the ancient astronomers looked into the night sky and saw Venus, they believed of it that it is visible in the evening. But this is precisely what the corresponding de re claim denies. Any appearance to the contrary is due to mistaking the de dicto claim - that the ancient astronomers did not believe that Phosphorus is visible in the evening-for the corresponding de re claim-that the ancient astronomers did not believe of Phosphorus that it is visible in the evening.

The open question argument and Frege's puzzle, when formulated in terms of Leibniz's law, are subject to the same diagnosis. In each case, reflection on the relevant epistemic circumstances establishes at most the truth of a de 
dicto claim; but the validity of these arguments requires that the relevant premises be understood as de re claims. However, we should not believe the corresponding de re claims-either because we have no reason to believe them or because we have positive reason to deny them. But if we should not believe the de re premises of these arguments, then neither should we believe their conclusions.

The apparent soundness of $\mathrm{OQA}_{\mathrm{LL}}$ and the puzzling character of $\mathrm{FP}_{\mathrm{LL}}$ each involves mistaking a de dicto claim for a de re claim. If we are prone to mistake substitutivity for Leibniz's law, this is perfectly explicable. In mistaking substitutivity for Leibniz's law, one is led to mistake instances of substitutivity for universal instantiations of Leibniz's law. But whereas universal instantiations of Leibniz's law are de re claims, instances of substitutivity need not be. Moreover, if there is unclarity about the content of the major premise, there will be a corresponding unclarity about the contents of the minor premises. So if the major premises of $\mathrm{OQA}_{\mathrm{LL}}$ and $\mathrm{FP}_{\mathrm{LL}}$ are universal instantiations of Leibniz's law but are mistaken for instances of substitutivity, then understanding the minor premises as true de dicto claims will result in the illusory soundness of these arguments.

\section{The Metalinguistic Formulations Again}

In section one I argued that if OQA and FP are sound, then the semantic principles, predicate and name transparency, are true. I suggested that these principles are false, and provisionally concluded that OQA and FP are unsound. Completing the case requires two things: First, one needs to explain why they are invalid, if they are; and explain which of their premises are false, if any are. Second, the explanation of the unsoundness of these arguments should be linked to the failures of predicate and name transparency. In this section, I will explain why OQA and FP are unsound. In the following section, I will explain the failures of predicate and name transparency.

Recall, OQA crucially involves a premise linking an epistemic feature of a question with its meaning. Specifically, OQA involved the premise:

If Q1 and Q2 mean the same, then if a competent speaker who understands the meaning of Q1 lacks sufficient evidence to know its answer, then a competent speaker who understands Q2 lacks sufficient evidence to know its answer.

(where Q1 and Q2 are the questions: Granted that $\mathbf{x}$ is $\mathbf{F}$, is $\mathbf{x} \operatorname{good}$ ? and Granted that $\mathbf{x}$ is good, is $\mathbf{x}$ good?). Moreover, I argued that, given certain plausible assumptions, this is a universal instantiation of Leibniz's law:

If the proposition expressed by Q1 = the proposition expressed by $\mathrm{Q} 2$, then if being open is a property of the proposition expressed by 
Q1, then being open is a property of the proposition expressed by Q2.

The intermediate conclusion of OQA is that the questions:

Q1 Granted that $\mathrm{x}$ is $\mathrm{F}$, is $\mathrm{x}$ good?

Q2 Granted that $\mathrm{x}$ is good, is $\mathrm{x}$ good?

differ in meaning and, hence, express distinct propositions. The argument purports to establish that they express distinct propositions by claiming that the proposition expressed by Q1 has a property that the proposition expressed by Q2 lacks. Specifically, whereas the proposition expressed by Q1 has the property of being open, the proposition expressed by Q2 lacks this property. By Leibniz's law, the propositions expressed by Q1 and Q2 must be distinct propositions.

It might be true that utterances of Granted that $\mathbf{x}$ is $\mathbf{F}$, is $\mathbf{x} \operatorname{good}$ ? normally convey an open proposition. But in order for the argument to be valid, the open proposition conveyed by this question must be the proposition expressed by it. After all, the relevant universal instantiation of Leibniz's law is a claim about the propositions expressed by these questions. So if the open proposition conveyed by Granted that $\mathbf{x}$ is $\mathbf{F}$, is $\mathbf{x} \operatorname{good}$ ? is not the proposition expressed, then we cannot validly conclude that the proposition expressed by it is distinct from the proposition expressed by Granted that $x$ is good, is $x \operatorname{good}$ ?

According to the descriptivist, $\mathbf{F}$ and good denote the same descriptive property. Suppose $\mathbf{F}$ is the predicate what we desire to desire. If what we desire to desire is identical to goodness and there is nothing more to the meaning of a predicate than the property it denotes, then what we desire to desire and good must be synonymous. Thus by compositionality:

Granted that $\mathrm{x}$ is what we desire to desire, is $\mathrm{x}$ good?

means the same as:

Granted that $\mathrm{x}$ is good, is $\mathrm{x}$ good?

The meaning of this question, the proposition that it expresses, is a singular query about what we desire to desire-it asks of what we desire to desire whether everything that instantiates it is good. Indeed it is the very same singular query that Granted that $\mathbf{x}$ is good, is $\mathbf{x}$ good? expresses. Though the question Granted that $\mathbf{x}$ is what we desire to desire, is $\mathbf{x} \operatorname{good}$ ? expresses a singular query, its utterance may pose some other query. The Moorean insight is that utterances of this question normally convey a descriptive 
query-say, whether everything that instantiates the property of being the object of a psychological attitude with such-and-such a functional role is good. The Moorean also correctly observes that this descriptive query is open. From these two observations it follows that the utterance of Granted that $\mathbf{x}$ is what we desire to desire, is $\mathbf{x}$ good? conveys an open descriptive query. But by hypothesis, the proposition expressed by Granted that $\mathbf{x}$ is what we desire to desire, is $\mathbf{x}$ good? is a singular query. Since the proposition conveyed is a descriptive query, it must be distinct from the proposition expressed. But if the proposition conveyed by Granted that $x$ is what we desire to desire, is $\mathbf{x}$ good? (the open proposition) is not the proposition expressed, then we cannot validly conclude that the proposition expressed by this question is distinct from the proposition expressed by Granted that $\mathbf{x}$ is good, is $x$ good?.

The problem with OQA then is this. A crucial intermediate conclusion of OQA is that the questions:

\section{Q1 Granted that $\mathrm{x}$ is $\mathrm{F}$, is $\mathrm{x}$ good?}

\section{Q2 Granted that $\mathrm{x}$ is good, is $\mathrm{x}$ good?}

differ in meaning and, hence, express distinct propositions. The subargument purports to establish that they express distinct propositions by claiming that the proposition expressed by Q1 has a property that the proposition expressed by Q2 lacks. Specifically, whereas the proposition expressed by Q1 has the property of being open, the proposition expressed by Q2 lacks this property. But this former claim has not been established. By hypothesis, the proposition expressed by Q1 is a singular query about F-ness-it asks of F-ness whether everything that instantiates it is good. Moreover, if one is agnostic about F-ness being goodness, one should be agnostic about it being an open question of F-ness whether everything that instantiates it is good. The most that has been established is that a descriptive query is open-that it is an open question whether everything that instantiates some property presented under the descriptive mode of presentation, $\mathrm{MP}_{\mathrm{F} \text {-ness }}$, is good. But as the descriptive query is a proposition distinct from the proposition expressed by Q1, this goes nowhere towards showing that the proposition expressed by this question is distinct from the proposition expressed by Q2.

Recall, FP itself crucially involved a premise linking an epistemic feature of a sentence with its meaning. Specifically FP involved the premise:

If $\mathrm{S} 1$ and $\mathrm{S} 2$ mean the same, then if a competent speaker possesses sufficient evidence to accept $\mathrm{S} 1$, then the speaker possesses sufficient evidence to accept S2 as well. 
(where S1 and S2 are the sentences: Hesperus is visible in the evening and Phosphorus is visible in the evening). Moreover, I argued that, given certain plausible assumptions, this is a universal instantiation of Leibniz's law:

If the proposition expressed by $\mathrm{S} 1$ = the proposition expressed by $\mathrm{S} 2$, then if having sufficient evidence in c to believe it is a property of the proposition expressed by $\mathrm{S} 1$, then having sufficient evidence in $\mathrm{c}$ to believe it is a property of the proposition expressed by $\mathrm{S} 2$.

The intermediate conclusion of FP is that:

$\mathrm{S} 1$ Hesperus is visible in the evening

S2 Phosphorus is visible in the evening

differ in meaning and, hence, express distinct propositions. The subargument purports to establish that they express distinct propositions by claiming that the proposition expressed by $\mathrm{S} 1$ has a property that the proposition expressed by S2 lacks. Specifically, whereas the proposition expressed by S1 has the property that the ancient astronomers possessed by sufficient evidence to believe it, the proposition expressed by S2 lacks this property. By Leibniz's law, the propositions expressed by $\mathrm{S} 1$ and $\mathrm{S} 2$ must be distinct propositions.

It might be true that the ancient astronomers lacked sufficient evidence to accept the sentence Phosphorus is visible in the evening. That is, it might be true that the ancient astronomers lacked sufficient evidence to believe the proposition conveyed by the utterance of this sentence. But Salmon (1986) observes that if the proposition conveyed by this utterance is not the proposition expressed, then the argument is invalid. After all, the relevant universal instantiation of Leibniz's law is a claim about the propositions expressed by these sentences. So if the proposition conveyed by Phosphorus is visible in the evening (the proposition that the ancient astronomers lacked sufficient evidence to believe) is not the proposition that it expresses, then we cannot validly conclude that the proposition expressed by it is distinct from the proposition expressed by Hesperus is visible in the evening.

According to the Millian, the meaning of a name is the object that it denotes. Since Hesperus and Phosphorus denote the same object, Venus, Hesperus and Phosphorus must be synonymous. Thus by compositionality:

Phosphorus is visible in the evening

means the same as: 
Hesperus is visible in the evening.

The meaning of Phosphorus is visible in the evening, the proposition that it expresses, is a singular proposition about Venus-it claims of the object Venus that it instantiates the property of being visible in the evening. Indeed it is the very same singular proposition that Hesperus is visible in the evening expresses. Though Phosphorus is visible in the evening expresses a singular proposition, its utterance may convey some other proposition. The Fregean's insight is that the utterance of Phosphorus is visible in the evening conveys a descriptive proposition-roughly, that Venus presented under the descriptive mode of presentation, visible in the morning, is visible in the evening. The Fregean also correctly observes that the ancient astronomers lacked sufficient evidence to believe this descriptive proposition. From these two observations it follows that the ancient astronomers lacked sufficient evidence to accept the sentence Phosphorus is visible in the evening (since the acceptance of a sentence is belief in the proposition conveyed by its utterance). But by hypothesis, the proposition expressed by Phosphorus is visible in the evening is a singular proposition. (N.B., we have not yet reached the conclusion of Frege's puzzle and so are still entertaining the truth of Millianism.) Since the proposition conveyed is a descriptive proposition, it must be distinct from the singular proposition expressed. But if the proposition conveyed by Phosphorus is visible in the evening (the proposition that the ancient astronomers lacked sufficient evidence to believe) is not the proposition expressed, then we cannot validly conclude that the proposition expressed by it is distinct from the proposition expressed by Hesperus is visible in the evening.

The problem with FP then is this. A crucial intermediate conclusion of FP is that:

\section{S1 Hesperus is visible in the evening}

S2 Phosphorus is visible in the evening

differ in meaning and, hence, express distinct propositions. The subargument purports to establish that they express distinct propositions by claiming that the proposition expressed by $\mathrm{S} 1$ has a property that the proposition expressed by S2 lacks. Specifically, whereas the proposition expressed by S1 has the property that the ancient astronomers possessed sufficient evidence to believe it, the proposition expressed by S2 lacks this property. But this latter claim has not been established. By hypothesis, the proposition expressed by S2 is a singular proposition about Venus. Moreover, this proposition has the property that the ancient astronomers possessed sufficient evidence to believe it-indeed, they had sufficient evidence to believe it each time they looked 
into the night sky and saw Venus. The most that has been established is that a descriptive proposition-that Venus presented under the descriptive mode of presentation, visible in the morning, is visible in the evening-lacks the property that the ancient astronomers possessed sufficient evidence to believe it. But as the descriptive proposition is distinct from the singular proposition expressed by S2, this goes nowhere towards showing that the proposition expressed by $\mathrm{S} 2$ is distinct from the proposition expressed by $\mathrm{S} 1$.

OQA and FP are subject to the same diagnosis. In each case, reflection on the relevant epistemic circumstances establishes at most that a descriptive query is open, and that the ancient astronomers lacked sufficient evidence to believe a descriptive proposition. But the validity of these arguments requires that a singular query be open, and that the ancient astronomers lacked sufficient evidence to believe a singular proposition. However, we should not believe these corresponding claims-either because we have no reason to believe them or because we have positive reason to deny them.

\section{The Manifest Image of Linguistic Practice}

Why are we prone to mistake the proposition conveyed by an utterance for the proposition expressed?

Nonliteral utterances, pace Davidson, are familiar examples of utterances that convey propositions distinct from the propositions expressed. In cases familiar from philosophers' examples, we are not tempted to identify the proposition conveyed by a nonliteral utterance with the (literal) proposition expressed. Many nonliteral utterances, however, are difficult to recognize as nonliteral. Yablo (2000, p. 214) has recently remined us of this:

They put a lot of hurdles in your path, there's a lot that could be said about that, there's no precedent for that, something tells me that you're right, there are some things better left unsaid, there is something that I forgot to tell you, viz. how to operate the lock, nothing gets my goat so much as chewing gum in class, a lot you can do for me, let's roll out the red carpet, the last thing I want is to..., their people have been rising in my esteem, I took her into my confidence, my patience is nearly exhausted, I'll take my chances, there's a trace of sadness in your eyes, a growing number of these leaks can be traced to Starr's office, she's got a lot of smarts, let's pull out all the stops, let's proceed along the lines suggested above.

Yablo (2000, p. 213) remarks of these examples that "with some of them you have to rub your eyes and blink twice before the nonliteral aspects shine through." But if we fail to recognize utterances containing these expressions as nonliteral, this is just because we are systematically mistaking the propositions that they normally convey with the propositions that they literally express.

This phenomena is not confined to the admittedly special case of nonliteral utterance. We have a general and systematic tendency to mistake the propositions normally conveyed by our utterances with the propositions that 
they literally express. The utterance of I am tired normally conveys that the speaker is tired; and until the work of Kaplan and Perry, many philosophers believed that the sentence expresses the proposition that the speaker is tired. But while the sentence normally conveys that the speaker is tired, that's not the proposition expressed by it relative to the context of utterance. Similarly, the utterance of John tried to lift the suitcase normally conveys that John failed to lift the suitcase; and until the work of Grice, many philosophers believed that the sentence expresses (or, at least, semantically entails) that John failed to lift the suitcase. But while the sentence normally conveys that John failed to lift the suitcase, that's not the proposition expressed (nor is it semantically entailed) by it in the context of utterance.

Moreover, competent speakers' general and systematic tendency to mistake the proposition conveyed by an utterance for the proposition expressed by the uttered sentence is perfectly explicable - at least given a natural picture of the epistemology of linguistic practice. What a competent speaker consciously understands by an utterance is what it conveys relative to the context of utterance. As Thau $(2002,160)$ puts it, what's conveyed by our utterances are observational entities of linguistic practice:

The information an utterance is used to convey is an observational entity of linguistic theory and the semantic value of an utterance is a theoretical postulate of that theory.

To adapt Sellars' phrase, what is conveyed by our utterances collectively constitute the manifest image of our linguistic practice.

I am not claiming that competent speakers are never conscious of the proposition expressed-the proposition expressed by an uttered sentence is sometimes conveyed, among other things, in the context of utterance. Nor am I claiming that competent speakers are never conscious of the proposition expressed as the proposition expressed-that a proposition conveyed is the proposition expressed by the uttered sentence is often manifest in the context of utterance. Nor am I claiming that competent speakers are never able to specify the proposition expressed by an uttered sentence-if a competent speaker understands quotation and the relevant semantic vocabulary, then the proposition expressed by a sentence can always be disquotationally specified. What's not guaranteed by a competent speaker's understanding, however, is that they know the proposition expressed by one sentence in a given context is the proposition expressed by another sentence in that context that means the same.

But if a competent speaker's understanding two sentences that mean the same is not sufficient for them to know that they express the same proposition in a given context, then the failures of predicate and name transparency are not only intelligible but predictable as well. Let $\mathbf{F}$ and $\mathbf{G}$ be predicates and 
let $\mathbf{S}[\ldots \mathbf{G} . .$.$] be the result of substituting \mathbf{G}$ in for at least one occurrence of $\mathbf{F}$ in $\mathbf{S}[\ldots \mathbf{F} \ldots$.$] . If a competent speaker can understand two sentences$ S[...F...] and S[...G...] that mean the same without knowing that they express the same proposition, then such a speaker can, without irrationality or pragmatic incoherence, accept one without accepting the other. Thus, supposing that good means just the same as some descriptive predicate $\mathbf{F}$, a competent speaker could, without irrationality or pragmatic incoherence, accept the sentence Everything good is good without accepting Everything $\mathbf{F}$ is good. But if they do, such a speaker would understand the synonymous predicates good and $\mathbf{F}$ but not possess sufficient evidence to know that they apply to the same range of things. Thus predicate transparency would fail. Similarly, name transparency would fail as well. Let $\mathbf{a}$ and $\mathbf{b}$ be names and let $\mathbf{S}[\ldots \mathbf{b} . .$.$] be the result of substituting \mathbf{b}$ in for at least one occurrence of $\mathbf{a}$ in $\mathbf{S}[\ldots \mathbf{a} \ldots .$. . If a competent speaker can understand two sentences $\mathbf{S}[\ldots \mathbf{a} . .]$. and $\mathbf{S}[\ldots \mathbf{b} \ldots .$.$] that mean the same without knowing that they express the$ same proposition, then such a speaker can, without irrationality or pragmatic incoherence, accept one without accepting the other. Thus, supposing that Hesperus means just the same as Phosphorus, a competent speaker could, without irrationality or pragmatic incoherence, accept the sentence Hesperus is visible in the evening without accepting Phosphorus is visible in the evening. But if they do, such a speaker would understand the synonymous names Hesperus and Phosphorus but not possess sufficient evidence to know that they denote to the same thing. Thus name transparency would fail as well.

\section{Bracketing Meaning Platonism}

The reformulations of the open question argument and Frege's puzzle in terms of Leibniz's law helped us to see what is wrong with their original, metalinguistic formulations. They did so because crucial premises linking epistemic features of sentences with their meanings were interpreted as universal instantiations of Leibniz's law. It was possible to so-interpret these principles given the following meaning platonist assumptions: There are propositions. Propositions are the objects of attitudes like belief, assertion, etc. Propositions are the primary bearers of truth and falsity. The meaning of a (context insensitive) sentence is the proposition that it expresses. Evidence is primarily evidence for the truth or falsity of a proposition. Propositions are primarily open or closed. The acceptance of a sentence is belief in the proposition conveyed by it in the context of utterance.

However, these meaning platonist assumptions, though in some ways quite natural, are controversial. Moreover, it is possible to accept the open question argument and Frege's puzzle as sound and not be a meaning platonist. So it would seem that the case against the metalinguistic versions of 
these arguments is hampered by an optional and controversial meaning platonism.

Nevertheless, if the picture of the epistemology of linguistic practice sketched in the previous section is approximately correct, then there is reason to reject these arguments as unsound that does not assume meaning platonism. Without making some platonist background assumptions, it is impossible to interpret the target principles as universal instantiations of Leibniz's law. So an antiplatonist who accepts these arguments as sound must understand the target principles as something other than universal instantiations of Leibniz's law. But that means that the target principles are open to denial in the way they could not be if they were understood as universal instantiations of Leibniz's law. Indeed, given how the theory/observation distinction is deployed within linguistic practice, there is reason to deny these principles so-interpreted.

Suppose that what's conveyed by our utterances collectively constitute the manifest image of linguistic practice. Suppose, that is, that the observational entities of linguistic practice, what a competent speaker consciously understands by an utterance, is what's conveyed by that utterance. But suppose that the meanings of uttered sentences are theoretical entities of linguistic practice, at least to this extent: that merely understanding two sentences is not sufficient for knowing that they mean the same. If a competent speaker's understanding two sentences that mean the same is not sufficient for knowing that they mean the same, then a competent speaker could, without irrationality or pragmatic incoherence, accept one without also accepting the other. But that means that the Fregean premise:

If $\mathrm{S} 1$ and $\mathrm{S} 2$ mean the same, then if a competent speaker possesses sufficient evidence in a context $\mathrm{c}$ to accept $\mathrm{S} 1$, then that speaker possesses sufficient evidence in c to accept $\mathrm{S} 2$ as well.

is false (on its antiplatonist interpretation). And a similar pattern of reasoning suffices to show that the Moorean premise:

If Q1 and Q2 mean the same, then if a competent speaker who understands Q1 lacks sufficient evidence to know its answers (in which case Q1 is open), then a competent speaker who understands Q2 lacks sufficient evidence to know its answer (in which case Q2 is open).

is itself false (on its antiplatonist interpretation). ${ }^{27}$

27 I would like to thank the participants of my UCL seminar given in Fall 2001 and the UCL faculty colloquia where versions of this material were presented. Special thanks to James Dreier, M.G.F. Martin, Véronique Munoz-Dardé, James Pryor, Mark van Roojen, Scott 


\section{Bibliography}

Armstrong, David, 1980: Nominalism and Realism, Universals and Scientific Realism Vol. I. Cambridge: Cambridge University Press.

Arnauld, Antoine, 1641/1984: "Fourth Set of Replies." The Philosophical Writings of Descartes, J. Cottingham, R. Stoothoff, and D. Murdoch (trs.). Cambridge: Cambridge University Press.

Boyd, Richard, 1988: "How to be a Moral Realist." G. Sayre-McCord (ed.) Essays on Moral Realism. Ithaca: Cornell University Press.

Brink, David, 1989: Moral Realism and the Foundations of Ethics. Cambridge: Cambridge University Press.

Burge, Tyler, 1986: "Frege on Truth.” L. Haaparanta and J. Hintikka (eds.) Frege Synthesized. Dordrecht: Reidel, pp. 97-154.

Cartwright, Richard, 1971/1987: "Identity and Substitutivity." In Philosophical Essays. Cambridge, MA: MIT Press, pp. 135-48.

Crane, Tim and D.H. Mellor, 1990: "There is No Question of Physicalism." Mind, 99, pp. 185-206.

Frege, Gottlob, 1892/1984: "On Sense and Meaning." B. McGuiness (ed.) Collected Papers on Mathematics, Logic, and Philosophy, pp. 157-77.

Gibbard, Alan, 1990: Wise Choices, Apt Feelings. Cambridge, MA: Harvard University Press.

Horgan, Terence and Mark Timmons, 1992: “Troubles for New Wave Moral

Semantics: The 'Open Question Argument' Revived.” Philosophical Papers, xxi, pp. 153-76.

Horwich, Paul, 1995: "Meaning, Use and Truth." Mind 104: 355-68.

Kripke, Saul, 1979/1988: “A Puzzle About Belief.” A. Margalit (ed.) Meaning and Use. Dordrecht: Reidel, pp. 239-83. Reprinted in N. Salmon and S. Soames (eds.) Propositions and Attitudes. Oxford: Oxford University Press, pp. 102-148.

, 1980: Wittgenstein: On Rules and Private Language. Cambridge, MA: Harvard University Press.

Moore, G.E, 1903: Principia Ethica. Cambridge: Cambridge University Press.

, 1912: Ethics. Oxford: Oxford University Press.

Putnam, Hilary, 1981: Reason, Truth and History. Cambridge: Cambridge University Press.

Rieber, Stephen, 1992: "Understanding Synonyms Without Knowing that They Are Synonymous." Analysis, 52, 4, pp. 224-8.

Richard, Mark, 1990: Propositional Attitudes: An Essay on Thoughts and How We Ascribe Them. Cambridge: Cambridge University Press.

Soames, Michael Thau, and an anonymous referee for their generous and helpful comments. 
Rosen, Gideon, 1997: "What is the Normativity of Meaning?" Unpublished manuscript.

Salmon, Nathan, 1986: Frege's Puzzle. Cambridge, MA: MIT Press. , 1989: "How to Become a Millian Heir." Nous 23, pp. 211-20. , 1990: "A Millian Heir Rejects the Wages of Sinn." C.A. Anderson and J. Owens (eds.) Propositional Attitudes: The Role of Content in Logic, Language, and Mind. Stanford, CA: CSLI, pp. 215-47.

Smith, Michael, 1986: "Should We Believe in Emotivism?" G. McDonald and C. Wright (eds.) Fact, Science and Morality: Essays on A.J. Ayer's Language, Truth and Logic. Oxford: Basil Blackwell, pp. 289-310.

Soames, Scott, 1986: "Substitutivity." J.J. Thomson (ed.) Being and Saying: Essays for Richard Cartwright. Cambridge, MA: MIT Press, pp. 99132.

1997: "Skepticism about Meaning: Indeterminacy, Normativity, and the Rule-Following Paradox." A. Kazmi (ed.) Meaning, Reference and Truth, Canadian Journal of Philosophy, supplementary volume 23.

Thau, Michael, 2002: Consciousness and Cognition. New York: Oxford University Press.

Yablo, Stephen, 2000: "Apriority and Existence." P. Boghossian and C. Peacocke (eds.) New Essays on the A priori. Oxford: Oxford University Press, pp. 197-228. 